\title{
Protein Engineering of Penicillinase as Affinity Ligands for Bioprocessing
}

\author{
TADAYUKI IMANAKA, ${ }^{\prime *}$ AKIO KURODA, ${ }^{1}$ AND HENRY Y. WANG ${ }^{2}$ \\ Department of Fermentation Technology, Faculty of Engineering, Osaka University, Yamadaoka, \\ Suita-shi, Osaka 565, Japan, ${ }^{1}$ and Department of Chemical Engineering, The University \\ of Michigan, Ann Arbor, Michigan 48109, U.S.A. ${ }^{2}$
}

Received 10 December 1988/Accepted 13 February 1989

\begin{abstract}
The active site and the substrate binding site of penicillinase ( $\beta$-lactamase) from Bacillus licheniformis were altered in this study so that the enzyme retains the specific binding capability to the $\beta$-lactam antibiotics, but fails to hydrolyze them. When Lys47 in the enzyme molecule was replaced by Ala47, the mutant protein PenP(KA) lost not only its catalytic activity but also the substrate binding ability. In contrast, when Ser44 was replaced by Ala, the mutant protein $\operatorname{PenP}\left(\mathbf{S A}_{\mathbf{A}}\right)$ lost its catalytic activity but still kept the substrate binding ability. It was found that PenP(SA) exhibited the characteristic association and dissociation with penicillin $G$, but the dissociation constant was much larger than expected. Possible use of this mutant protein as an affinity ligand is also discussed.
\end{abstract}

The affinity adsorption for small molecular weight products such as antibiotics is often limited because of the lack of effective biospecific ligands. Conventional separation processes for these compounds mainly utilize a combination of non-specific methods such as chromatography, ion-exchange, and physical adsorption. Many of these compounds interact specifically with different enzymes in a number of biological systems. For instance, $\beta$-lactam antibiotics interact with microbial $\beta$-lactamases, which hydrolyze these antibiotics to biologically inactive molecules. Immobilized $\beta$-lactams have been used as affinity ligands to purify several types of $\beta$-lactamases (1-3). However, the reciprocal system using immobilized enzymes for purifying valuable $\beta$-lactams cannot be applied directly because these enzymes not only specifically bind to the $\beta$-lactams but also catalyze their hydrolyses.

Recent advances in protein engineering now permit the modification of any gene for designing novel proteins not found in nature using techniques such as site-directed mutagenesis (4). This had led to the possibility of designing enzymes by manipulating the active site so that it retains the capability of specific recognition and reversible binding to the substrate but fails to catalyze its degradation. Such a redesigned enzyme would be a powerful affinity ligand for its corresponding substrate. In this study we have demonstrated the feasibility of this concept using $\beta$-lactamase from Bacillus licheniformis.

\section{MATERIALS AND METHODS}

Bacterial strains and plasmids The bacterial strains and plasmids used are listed in Table 1. penP, penI, and pen $J$ are the penicillinase ( $\beta$-lactamase) gene, its repressor gene, and antirepressor gene from $B$. licheniformis ATCC 9945 a, respectively.

Transformation Transformation of Escherichia coli with plsmid DNA was done as described previously (6). Transformants were selected on $\mathrm{L}$ agar (6) containing $20 \mu \mathrm{g}$ of tetracycline (Tc) per $\mathrm{ml}$. Transformation of

\footnotetext{
${ }^{*}$ Corresponding author.
}

competent Bacillus subtilis cells was also performed as previously described (5). B. subtilis transformants were selected on $\mathrm{L}$ agar containing $25 \mu \mathrm{g}$ of Tc per ml.

DNA manipulations and analysis Preparation of plasmid DNA, cleavage and ligation of DNA, gel electrophoresis for DNA analysis and isolation were all performed as described previously (8). DNA was sequenced by the dideoxy method (7), with an M13 sequencing kit (Takara Shuzo Co., Kyoto). The sequencing was done on both strands. Site-directed mutagenesis was performed with the in vitro mutagenesis system (Amersham Japan, Tokyo).

Penicillinase production and enzyme assay $\quad B$. subtilis carrying the pen $P$ gene was cultivated overnight in $\mathrm{CH} / \mathrm{S}$ medium $(8)$ at $37^{\circ} \mathrm{C}$. A sample $(50 \mathrm{ml})$ of the preculture was inoculated in the fresh medium $(5 l)$ and cultivated in a $10 /$ fermentor (Type MD-500, Marubishi Bioeng Co., Tokyo) for $18 \mathrm{~h}$. The supernatant of the culture broth obtained by centrifugation $(8000 \mathrm{~g}, 10 \mathrm{~min})$ was used as the enzyme source. Penicillinase was purified by phosphocellulose treatment, carboxymethylcellulose chromatography and Sephadex G-100 chromatography as described previously (9).

Penicillinase was assayed by the iodometric method as described previously (6). The method for detection of penicillinase-positive colonies on LP plates ( $\mathrm{L}$ agar containing $0.75 \%(\mathrm{w} / \mathrm{v})$ polyvinyl alcohol) has also been described previously (6).

Protein assay Protein concentration was determined by the BCA method (protein assay kit, Pierce Co. Rockford, Illinois, U.S.A.). Bovine serum albumin was used as a standard.

Immunoprecipitation Anti-penicillinase serum was prepared by subcutaneously injecting a rabbit with $1.0 \mathrm{mg}$ of purified penicillinase in complete Freund's adjuvant, boosting subcutaneously at two weeks with $1.0 \mathrm{mg}$ of purified penicillinase in complete adjuvant, and bleeding beginning two weeks later. The sample was coagulated at room temperature for $30 \mathrm{~min}$, and then kept at $4^{\circ} \mathrm{C}$ overnight. After centrifugation, the supernatant fraction was used as anti-penicillinase serum. Immunoprecipitation on 
TABLE 1. Bacterial strains and plasmids

\begin{tabular}{|c|c|c|}
\hline Bacteria/Plasmids & Characteristics & Reference \\
\hline \multicolumn{3}{|l|}{ Bacteria } \\
\hline B. subtilis MI113 & trpC2 arg-15 thr-5 hsmM hsrM & (5) \\
\hline E. coli $\mathrm{C} 600-1$ & leu-6 thr-1 supE44 lacY1 tonA21 hsdR hsdM Trp & (6) \\
\hline E. coli JM 109 & $\begin{array}{l}\text { recA1 Alacpro endAI gyrA96 thi-1 hsdRI7 supE } 44 \text { relAl } \\
\mathrm{F}^{\prime}\left[\text { traD36pro } A B \text { lacI }{ }^{\circ} Z M I 5\right]\end{array}$ & (7) \\
\hline \multicolumn{3}{|l|}{ Plasmid } \\
\hline \multicolumn{3}{|l|}{ For B. subtilis } \\
\hline pPTB50 & $\mathrm{Tc}^{r}$ pen $P^{+}$penI penJ & (8) \\
\hline pPTB50 SA & $\operatorname{Te}^{r}$ penP(SA), Ser 44 was replaced by Ala & This work \\
\hline pPTB50 ST & Ter penP(ST), Ser44 was replaced by Thr & This work \\
\hline pPTB50 KA & $\mathrm{Tc}^{r}$ penP(KA), Lys 47 was replaced by Ala & This work \\
\hline \multicolumn{3}{|c|}{ 美 } \\
\hline pTTE 11 & ${ }^{\mathrm{T}} \mathrm{r}$ penP $P^{-}$penI penJ & $(6)$ \\
\hline pTTE11 SA & $\mathrm{Tc}^{r}$ penP(SA), Ser 44 was replaced by Ala & This work \\
\hline pTTEI1 ST & $\mathrm{Tc}^{\mathrm{I}}$ penP(ST), Ser44 was replaced by Thr & This work \\
\hline pTTE $11 \mathrm{KA}$ & $\mathrm{Tc}^{\mathrm{r}}$ penP(KA), Lys 47 was replaced by Ala & This work \\
\hline
\end{tabular}

plate was performed by the gel-diffusion method (10).

Penicillin binding assay Characteristics of penicillin binding were examined by the gel filtration method (11) and the equilibrium dialysis method (12). Benzyl[ $\left[{ }^{14} \mathrm{C}\right]-$ penicillin potassium (labeled PenG) (Amersham Japan, Tokyo) was used as rediolabeled substrate. A Sephadex G-25 column $(7 \times 250 \mathrm{mn})$ was used in the gel filtration method. The equilibrium dialysis method was performed under the following conditions using semipermeable membrane.

Compartment A: $2.6 \times 10^{-5} \mathrm{M}$ PenP(SA) and $3.7 \times 10^{-5}$ $\mathrm{M}\left[{ }^{14} \mathrm{C}\right]-\mathrm{PenG}$ in $0.1 \mathrm{M}$ phosphate buffer $(\mathrm{pH} 7.0)$

Compartment B: 0.1 M phosphate buffer ( $\mathrm{pH} 7.0$ )

Chemicals Penicillin $G$ was purchased from Meiji Seika Co., Tokyo. Chemically synthesized oligonucleotides were from Applied Biosystem's Japan Co., Osaka. The antibiotics, restriction endonucleases, ligase, and all of the reagents used here were purchased from the same companies and laboratories as in previous work (6, $8,9)$, unless otherwise noted.

\section{RESULTS AND DISCUSSION}

Active site of $\boldsymbol{B}$. licheniformis penicillinase Strominger et al. (13) compared the amino acid sequences of penicillin binding sites and their flanking regions for various $\beta$-lactamases, carboxy peptidase, and penicillin binding proteins (PBP) (Table 2). The amino acid sequence, Ser-X-X-Lys, was found to be the consensus sequence for the penicillin binding site. Since the active site of Bacillus cereus $\beta$-lactamase type I was known to be Ser91 of the immature enzyme (14), the amino acid sequence was aligned and compared with that of $B$. licheniformis penicillinase (data not shown). The sequence, Ser91-X-XLys94, and its flanking region of $B$. cereus enzyme are very similar to the sequence, Ser85-X-X-Lys88, and the flanking region of $B$. licheniformis immature penicillinase, respectively. Ser85 corresponds to Ser44 of exo-small penicillinase, because the immature enzyme is cleaved at Lys42 to give an extracellular enzyme (15). Accordingly, it was inferred that Ser44 of extracellular penicillinase of $B$. licheniformis might function as an active site.

Reaction mechanism of penicillinase The mechanism of reaction of $B$. cereus penicillinase was inferred as follows: The hydroxyl group of the active site Ser is used to form acyl-enzyme intermediate. The intermediate is hydrolyzed, giving penicilloic acid as the product (16).

Herzberg and Moult (17) determined the tertiary structure of Staphylococcus aureus $\beta$-lactamase. The enzyme structure was compared with that of the serine protease from Streptomyces griseus (18). It was found that the steric conformation of Glu166, Lys 73 and Ser70 (active site) of the $\beta$-lactamase was nearly identical to that of Asp 102, His57 and Ser 195 (active site) of the serine protease, all of which are essential for catalytic activity (Fig. 1) $(17,18)$. His 57 of the serine protease activates Ser 195 by providing an electron. Likewise, Lys 73 of the $\beta$-lactamase might function to activate Ser70. Therefore, it was inferred that Lys 47 of $B$. licheniformis penicillinase could function to activate the putative active site Ser44.

TABLE 2. Consensus sequence of penicillin binding regions

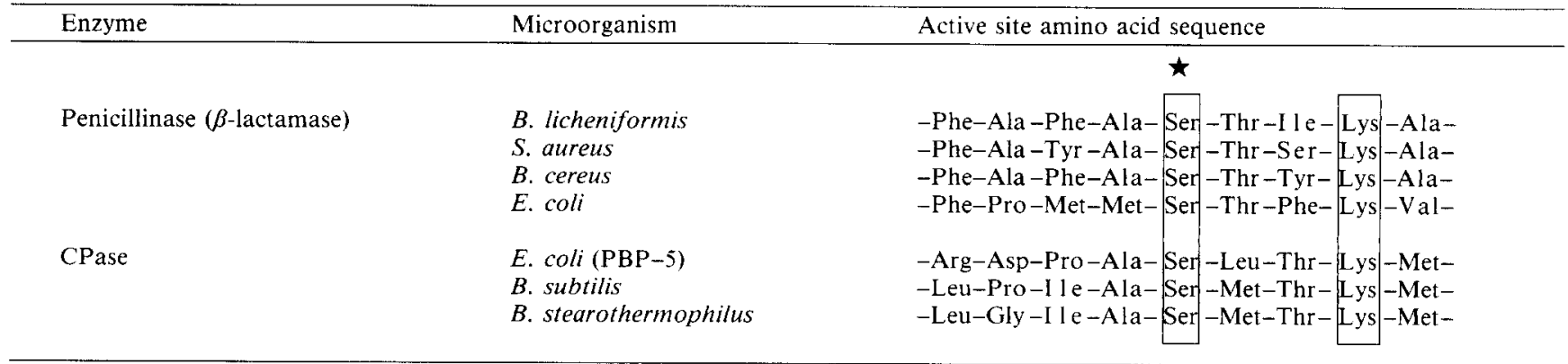

$\star$, Active center. 


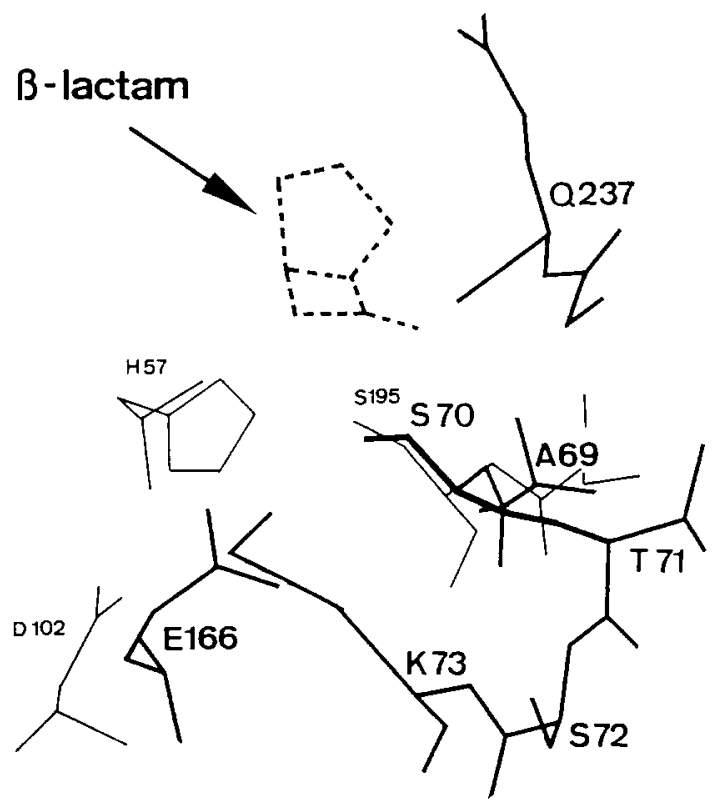

FIG. 1. Comparison of three dimensional structures in the active center regions of Staphy, aureus $\beta$-lactamase $(-)(17)$ and serine protease of $S$. griseus (_) (18).

Creation of mutant proteins of penicillinase To eliminate the catalytic activity of $B$. licheniformis penicillinase, the following amino acid replacements were attempted.
TABLE 3. Synthetic oligonucleotides used

\begin{tabular}{cc}
\hline & Oligonucleotide \\
\hline Ser44 $\rightarrow$ Ala44 & s'GCTTTTGCGGCGACGAT $^{\star}$, \\
Ser44 $\rightarrow$ Thr44 & s'GCTTTTGCGACGACGAT \\
Lys47 $\rightarrow$ Ala47 & s'TCGACGATTGCGGCTTAAAC \\
\hline
\end{tabular}

$\star$, Base substitution.

(i) To block the formation of the acyl-enzyme intermediate, the hydroxyl group of Ser 44 was eliminated, i.e. Ser44 was replaced by Ala44.

(ii) To inhibit the formation of the acyl-enzyme intermediate, a methyl group was added to Ser 44 as the steric interference, i.e. Ser 44 was replaced by Thr 44 .

(iii) To eliminate the catalytic activity, Lys47 was replaced by Ala 47 .

These amino acid substitutions were performed by sitedirected mutagenesis as shown in Fig. 2. B. licheniformis penicillinase gene, penP, was cloned in pPTB50. The PstIClaI fragment of penP was cloned in Pst I-AccI sites of phage M13. Single-stranded DNA was isolated from the recombinant phage M13penP, and was annealed by the synthetic oligonucleotide carrying mutation (Table 3 ). After in vitro mutagenesis, the DNA was used for the transfection of $E$. coli TG1. The mutation was confirmed by DNA sequencing. The PstI-Bg/II fragment of pTTE1I was substituted with the PstI-BglII fragment containing mutation. The mutant plasmids (amino acid substitutions, Ser44 $\rightarrow$ Ala44, Ser44 $\rightarrow$ Thr44, Lys47 Ala47) were

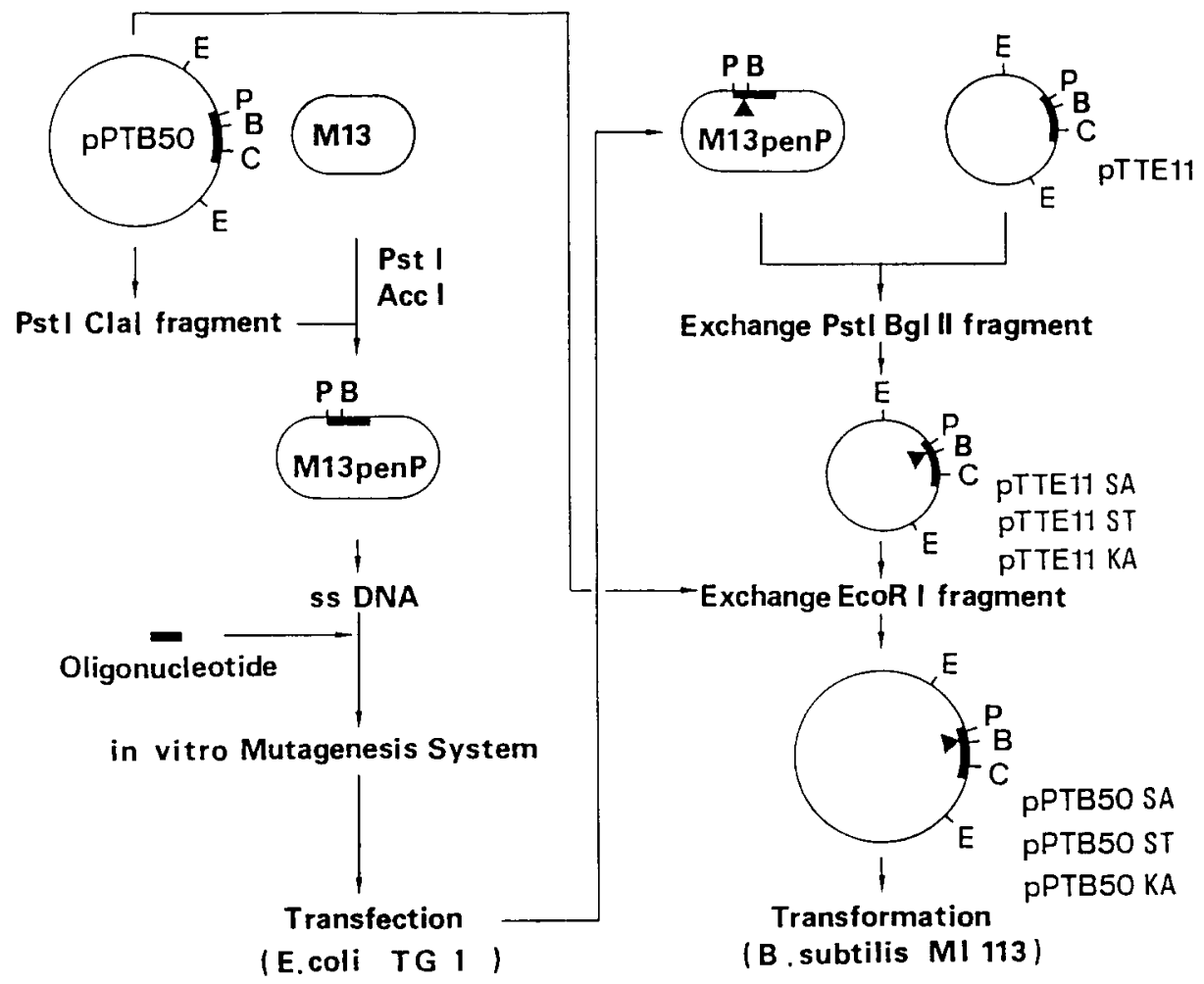

FIG. 2. Strategy for the construction of mutant enzyme genes by site-directed mutagenesis. For details, see text. 

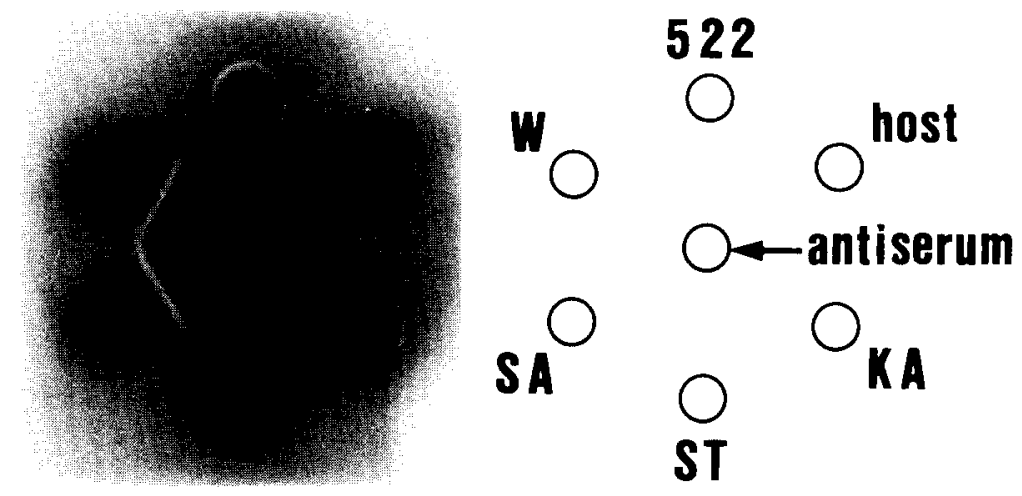

FIG. 3. Immunoprecipitation by gel-diffusion method. Culture supernatants of $B$. subtilis without plasmid and the strain carrying p TB522 (vector), pPTB50, pPTB50SA, pPTB50ST, or pPTB50KA are indicated by host, 522, W, SA, ST, or KA, respectively.

designated pTTE11SA, pTTE11ST, and pTTE11KA, respectively. The EcoRI fragment of pPTB50 was replaced by the EcoRI fragments of these plasmids, pTTE11SA, pTTE11ST, and pTTE11KA. The mutant plasmids thus obtained in $B$. subtilis were designated pPTB50SA, pPTB50ST, and pPTB50KA, respectively.

B. subtilis MI113 carrying wild-type penP or its mutants was cultivated in $\mathrm{L}$ broth at $37^{\circ} \mathrm{C}$ for $12 \mathrm{~h}$, and the penicillinase activity was assayed. Although wild-type penP carrier produced a large amount of penicillinase ( 2250 units $/ \mathrm{ml}$ ), no enzyme activity was observed for three mutant plasmid carriers. To examine whether or not the mutant pen $P$ protein could be secreted from host cells, immuno-precipitation was performed (Fig. 3). Antipenicillinase serum was in the center well, and the culture supernatants of plasmid carriers were placed in the surrounding wells. No precipitation was observed for $B$. subtilis (host) and the pTB522 carrier, while others exhibited fused precipitation bands. It is clear from Fig. 3 that the mutant proteins PenP(SA), PenP(ST), and PenP(KA) from pPTB50SA, pPTB50ST, and pPTB50KA, respectively, were secreted in the culture media. These results showed that the mutant proteins were secreted but had lost the catalytic activity entirely.

Purification of mutant proteins of penicillinase Purification of mutant proteins was performed by the method used for the wild-type enzyme. Since PenP(ST) was found to be difficult to be purified in a large amount, subsequent work was focused on PenP(SA) and PenP(KA) only. These two mutant proteins were purified and subjected to SDS-polyacylamide gel electrophoresis (Fig. 4). Both proteins showed single bands, with the same migration. PenP(SA) and PenP(KA) exhibited fused precipitation bands with purified penicillinase (wild type) (Fig. 4)

Penicillin binding assay for PenP(SA) and PenP(KA) For the penicillin binding assay, a Sephadex G-25 column

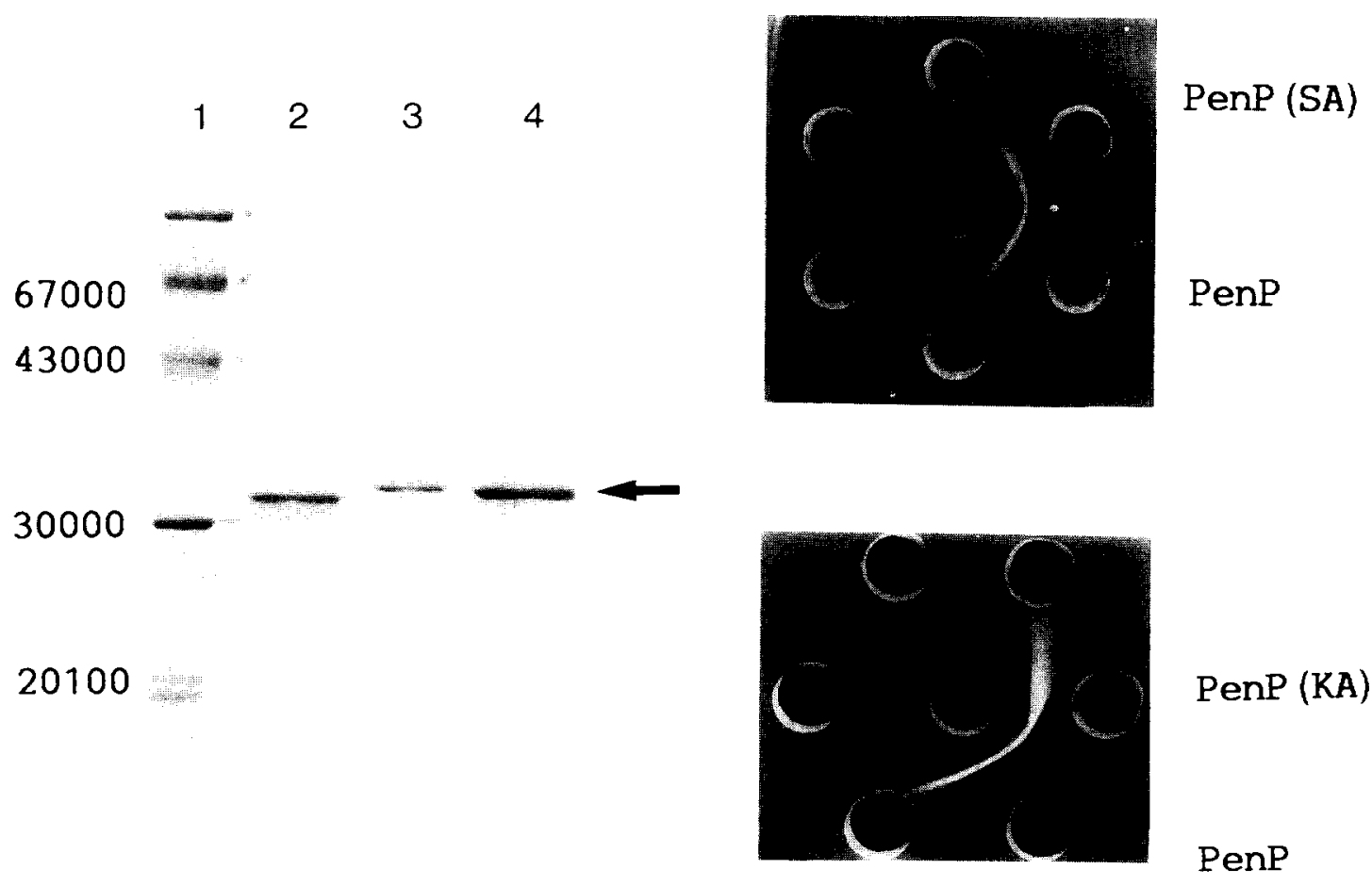

FIG. 4. SDS-polyacrylamide gel electrophoresis and immunoprecipitation of penicillinase and its mutant proteins, PenP(SA) and PenP(KA). Lane 1, molecular weight standard; lane 2, wild-type penicillinase (PenP); lane 3, PenP(SA); lane 4, PenP(KA). 


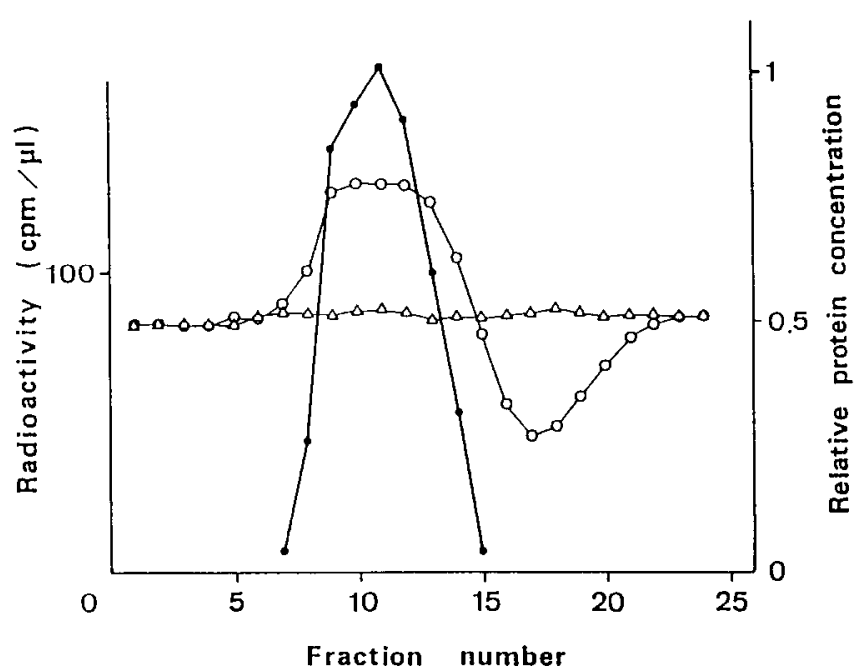

FIG. 5. Penicillin binding assay for PenP(SA), using gel filtration column chromatography. 0 , PenP(SA) $(2.2 \mathrm{n}$ mole $)+\left[{ }^{14} \mathrm{C}\right]-$ PenG; $\triangle$, BSA $(200 \mu \mathrm{g})+\left[{ }^{14} \mathrm{C}\right]$-PenG. Radioactivity of $\left[{ }^{14} \mathrm{C}\right]-\mathrm{PenG}$ was measured. $\bullet$, PenP(SA).

was equilibrated with $0.1 \mathrm{M}$ phosphate buffer ( $\mathrm{pH} 7.0$ ) containing $\left[{ }^{14} \mathrm{C}\right]$-PenG $\left(0.85 \times 10^{-6} \mathrm{M}\right)$. A mixture $(100 \mu \mathrm{l})$ of PenP(SA) $(2.2 \mathrm{nmol})$ and $\left[{ }^{14} \mathrm{C}\right]-\mathrm{PenG}\left(0.85 \times 10^{-6} \mathrm{M}\right)$ in $0.1 \mathrm{M}$ phosphate buffer $(\mathrm{pH} \mathrm{7.0)}$ was applied to the abovementioned column, and eluted by the phosphate buffer plus $\left[{ }^{14} \mathrm{C}\right]-P e n G$. The elution pattern of $\left[{ }^{14} \mathrm{C}\right]-\mathrm{Pen} G$ is shown in Fig. 5. When protein PenP(SA) was eluted, high radioactivity was detected. Following this peak, a decrease in radioactivity was observed. In contrast, when PenP(SA) was replaced by bovine serum albumin (BSA, $200 \mu \mathrm{g}$ ), no such increase and decrease of $\left[{ }^{14} \mathrm{C}\right]-\mathrm{PenG}$ were observed. These results show that PenG interacted specifically with PenP(SA). When PenP(KA) was used instead of PenP(SA) in a similar column, no such association between PenP(KA) and PenG was observed. This fact indicates that Lys47 in the penicillinase is responsible for the

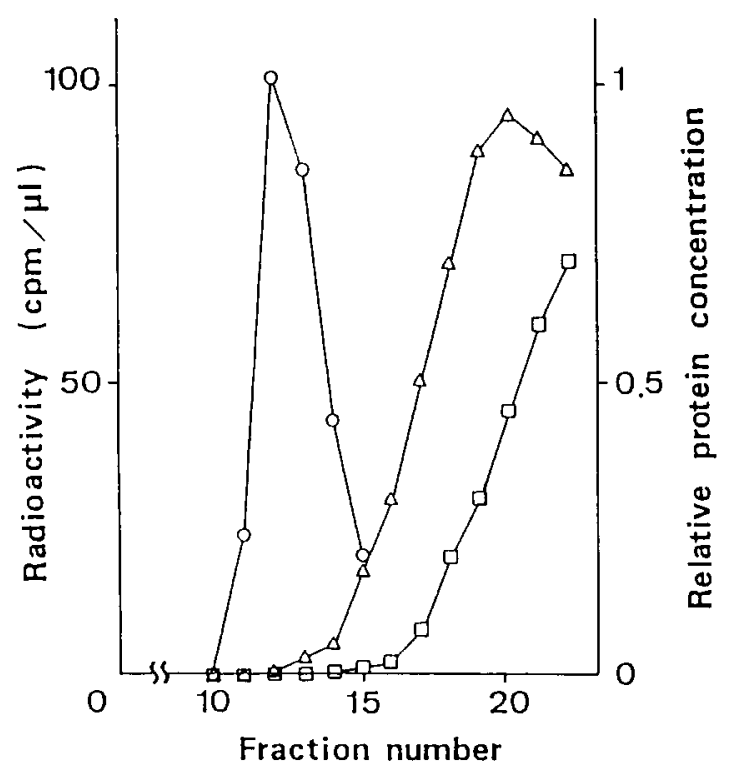

FIG. 6. Penicillin binding assay for PenP(SA). $\square,\left[{ }^{14} \mathrm{C}\right]-\mathrm{PenG} ; \triangle$, $\left[{ }^{14} \mathrm{C}\right]-\mathrm{PenG}+\mathrm{PenP}(\mathrm{SA})$. Radioactivity of $\left[{ }^{14} \mathrm{C}\right]-\mathrm{PenG}$ was measured. $\checkmark$. PenP(SA). For details, see text. binding of PenG.

To examine the characteristics of the association and dissociation between PenP(SA) and PenG, different types of column chromatography were carried out. A Sephadex G-25 column was equilibrated with $0.1 \mathrm{M}$ phosphate buffer $\left(\mathrm{pH} \mathrm{7.0)}\right.$, and a mixture $\left(100 \mu \mathrm{l}\right.$, prewarmed at $30^{\circ} \mathrm{C}$ for $10 \mathrm{~min})$ of PenP(SA) $(0.5 \mathrm{nmol})$ and $\left[{ }^{14} \mathrm{C}\right]-\mathrm{PenG}(4 \mathrm{nmol})$ in $0.1 \mathrm{M}$ phosphate buffer $(\mathrm{pH} 7.0)$ was applied to the column. The elution pattern is shown in Fig. 6. The peak fractions of PenP(SA) and PenG were no. 12 and no. 20, respectively. In other words, the protein passed through the column first, and then PenG was eluted. When only $\left[{ }^{14} \mathrm{C}\right]-$ Pen $\mathrm{G}$ was applied to the same column, the antibiotic was eluted more slowly than in the former case. These data indicate that PenG-PenP(SA) complex was dissociated during the process of column chromatography.

To assess the dissociation constant for the PenGPenP(SA) system, the equilibrium dialysis method was performed. The dissociation constant was determined to be $2.0 \times 10^{-3} \mathrm{M}$. If the mutant protein is used as an affinity ligand for PenG, the dissociation constant should be, in general, less than $10^{-5} \mathrm{M}$. In fact, the dissociation constant for the IgG-domain B (of protein A) complex is reported to be $2.2 \times 10^{-8} \mathrm{M}(19)$.

Despite the weak binding of PenP(SA) with PenG, it may have more proper binding constants with respect to other $\beta$-lactam antibiotics. This mutant protein may be useful in affinity chromatographic separation and bioscreening for new, potent $\beta$-lactam antibiotics from nature. We are currently investigating the possibilities in our laboratory.

\section{ACKNOWLEDGMENT}

H. Y. Wang acknowledges the financial support of NSF (ECE8612969).

\section{REFERENCES}

1. Crane, L.J., Bettinger, G. E., and Lampen, J. O.: Affinity chromatography purification of penicillinase of Bacillus licheniformis $749 / \mathrm{c}$ and its use to measure turnover of the cell bound enzyme. Biochem. Biophys. Res. Commun., 50, 220-227 (1973).

2. Eriquez, L. A. and D'amato, R. F.: Purification by affinity chromatography and properties of a $\beta$-lactamase isolated from Neisseria gonorrhoeae. Antimicrob. Ag. Chemother., 15, 229234 (1979).

3. Coombe, R. G. and George, A.M.: A rapid method for the purification of $\beta$-lactamase from Bacillus cereus by affinity chromatography. Anal. Biochem., 75, 652-655 (1976).

4. Ulmer, K. M.: Protein engineering. Science, 219, 666-667 (1983).

5. Imanaka, T., Fujii, M., and Aiba, S.: Isolation and characterization of antibiotic resistance plasmids from thermophilic bacilli and construction of deletion plasmids. J. Bacteriol., 146, 1091-1097 (1981).

6. Imanaka, T., Tanaka, T., Tsunekawa, H., and Aiba, S.: Cloning of the genes for penicillinase, pen $P$ and penI, of Bacillus licheniformis in some vector plasmids and their expression in Escherichia coli, Bacillus subtilis, and Bacillus lichenilformis. J. Bacteriol., 147, 776-786 (1981).

7. Messing, J.: New M13 vectors for cloning. Methods Enzymol., 101, 20-78 (1983).

8. Imanaka, T., Himeno, T., and Aiba, S.: Effect of in vitro DNA rearrangement in the $\mathrm{NH}_{2}$-terminal region of the penicillinase gene from Bacillus licheniformis on the mode of expression in Bacillus subtilis. J. Gen. Microbiol., 131, 1753-1763 (1985).

9. Imanaka, T., Oshihara, W., Himeno, T., and Aiba, S.: Comparative studies on extracellular penicillinases of the same struc- 
tural gene, penP, expressed in Bacillus licheniformis and Bacillus subtilis. J. Gen. Microbiol., 129, 2621-2628 (1983).

10. Gray, D. F.: Immunology, F. W. Cheshire Pty. Ltd., Melbourne (1970).

11. Hummel, J. P. and Dreyer, W. J.: Measurement of proteinbinding phenomena by gel filtration. Biochim. Biophys. Acta, 63, 530-532 (1962).

12. Englund, P. T., Huberman, J. A., Jovin, T. M., and Kornberg, A.: Enzymatic synthesis of deoxyribonucleic acid. J. Biol. Chem., 244, 3038-3044 (1969).

13. Waxman, D. J. and Strominger, J. L.: Penicillin-binding proteins and the mechanism of action of $\beta$-lactam antibiotics. Ann. Rev. Biochem., 52, 825-869 (1983).

14. Knott-hunziler, V., Waley, S. G., Orlek, B. S., and Sammes, P. G.: Penicillinase active sites: labeling of serine-44 in $\beta$-lactamase I by $6 \beta$-bromopenicillanic acid. FEBS Lett., 99, 59-61 (1979).
15. Crane, L. J. and Lampen, J. O.: Bacillus licheniformis $749 / \mathrm{C}$ plasma membrane penicillinase, a hydrophobic polar protein. Arch. Biochem. Biophys., 160, 655-666 (1974).

16. Cohen, S. A. and Pratt, R. F.: Inactivation of Bacillus cereus $\beta$ lactamase I by $6 \beta$-bromopenicillanic acid: mechanism. Biochem., 19, 3996-4003 (1980).

17. Herzberg, O. and Moult, J.: Bacterial resistance to $\beta$-lactam antibiotics: crystal structure of $\beta$-lactamase from Staphylococcus aureus $\mathrm{PC} 1$ at $2.5 \AA$ resolution. Science, 236, 694-701 (1987).

18. Fujinaga, M., Read, R. J., Sielecki, A., Ardelt, W., Laskowski, M. Jr., and James, M. N. G.: Refined crystal structure of the molecular complex of Streptomyces griseus protease B, a serine protease, with the third domain of the ovomucoid inhibitor from turkey. Proc. Natl. Acad. Sci. USA, 79, 4868-4872 (1982).

19. Myhre, E. B. and Knonvall, G.: Immunochemical aspects of Fc-mediated binding of human IgG subclasses to group A, C and G streptococci. Mol. Immun., 17, 1563-1573 (1980). 